Apprenticeship as a mode of learning and model of education

Stephen Billett, Griffith University, Australia

\begin{abstract}
Apprenticeships are usually seen, in contemporary times, as a model of education focused on occupational preparation, albeit manifested in different ways across nation states. However, throughout human history, the majority of occupational preparation has been premised upon apprenticeship as a mode of learning, that is, as preparation and ongoing learning arising mainly through active and interdependent engagement by apprentices in their work, rather than their being taught or directly guided by more experienced practitioners. Whilst both conceptions are important, the apprenticeship mode of learning is also central to the success of educational models, such as contemporary apprenticeships and the ongoing development of workers' occupational capacities and subjectivities. So, although apprenticeship has become viewed as a model of education associated with initial occupational preparation whose specific form is shaped by societal sentiment and governmental preference and imperatives, it is important to understand and emphasise apprenticeship as a mode of learning, not restricted to initial learning of an occupation. This consideration seems particularly salient for those of us living in schooled societies that often privilege education provisions over individuals' learning, yet which are seeking to enhance the efficacy of individuals' active learning across working life.
\end{abstract}

\title{
Apprenticeship as a mode of learning and model of education
}

Currently, apprenticeships are usually seen as models of education focused on initial occupational preparation, usually for young people, albeit manifested in distinct ways across nation states. Some of these models are largely premised on workplace experiences, with apprentices being employees and positioned as novice practitioners (Chan, 2013; Deissinger and Hellwig, 2005). Others comprise programs largely enacted through educational institutions, with apprentices being students (Berglund and Loeb, 2013), and then there are variations between these two kinds (e.g. in Denmark and Norway). However, across human history, most occupational preparation has arisen through apprenticeship as a mode of learning, not through these models of education; that is, it has arisen mainly through learners' active and interdependent engagement in occupational tasks, not through being taught or directly guided, and rarely in hybrid settings (i.e. educational institutions) established to promote that learning (Billett, 2014). Rather than viewing this mode as being just learning "on the job", it is characterised as being mediated by learners themselves, rather than the kinds of activities and interactions though which others (e.g. teachers, practitioners) directly attempt to mediate that learning (e.g. teaching and direct guidance). Whilst both conceptions are important, the apprenticeship mode of learning is also central to the success of educational models, such as contemporary models of apprenticeships, and in building learners' occupational capacities and subjectivities across working lives. Hence, whilst contemporary apprenticeships are usually viewed as educational models, they need also to be understood as a mode of learning to be engaged with by those wishing to develop occupational capacities and sustain them across lengthening working lives.

Having set out some premises upon which its case is founded, the paper progresses by, first, discussing some current versions and characteristics of apprenticeship as models of education. Then, the more long-standing and practised tradition of apprenticeship as a mode of learning is discussed, 
including its central role in societal progress and continuity. Having elaborated apprenticeship as mode of learning, consideration is then given to three practices upon which this learning can be guided and supported in contemporary times. These comprise (a) practice curriculum, (b) practice pedagogies, and (c) learners' personal epistemologies. Finally, briefly advanced are some implications for contemporary apprenticeships. The key argument here is that, across human history, the vast majority of learning required for occupational preparation seems to have arisen through individuals' personally-mediated learning, rather than being taught or directly guided by more expert partners. Hence, there is a need to acknowledge the central role that individuals' active learning makes in both work settings and educational settings and programs.

\section{Premises for understanding learning through apprenticeships}

To understand and appraise apprenticeship as both a mode of learning and model of education, it is helpful to advance premises through which this case can be comprehended. First and perhaps foremost is that as individuals engage in everyday thinking and acting they are also learning (Rogoff and Lave, 1984). There is no separate and distinct process of learning that humans engage in other than that which arises through their construing from experience and constructing what they know, can do and value through and from that experience. This premise is supported by diverse perspectives on human learning and development. Both cognitive (Anderson, 1993; Shuell, 1990; Van Lehn, 1989) and social constructivist (Rogoff, 1990) views advance this proposition, as do genetic epistemologists (Piaget and Inhelder, 1973), some developmental perspectives (e.g. Baldwin, 1894) and contemporary anthropological accounts (e.g. Hasse, 2014; Lave, 1993). It is the learning that arises from experiences earlier in individuals' lives (i.e. premediately) that generates what individuals know, can do and value, which in turn shapes how and what they learn through subsequent experiences (Valsiner, 2000). So, for instance, as individuals engage with activities or experiences that are novel for them, most likely new learning arises, as they may come to understand, know or value in new ways (Billett, 2001). Even when encountering experiences that are familiar, learning arises. That learning is associated with honing, refining or making links and associations with what they already know, can do and value, which are essential to the learning of occupational capacities. Yet, this process of learning is necessarily person-dependent (Billett, 2003; Valsiner, 2000). What for one individual will be a novel experience, for another will be routine or familiar. Hence, the "same" experience can lead to quite different outcomes or legacies for individuals. Also, individuals' processes of experiencing are premised upon intentions, interest, values (i.e. dispositions) (Perkins et al., 1993) that have arisen through experiences that have had across their life histories. Therefore, how individuals construe what they experience, direct their efforts and construct legacies of particular experiences are all central to individuals' learning.

Secondly, as individuals engage in occupational tasks they are also engaged in the remaking of that occupation (Donald, 1991). This remaking occurs as they address particular work problems or challenges and as they undertake tasks generated in specific circumstances and as directed towards particular goals (Billett et al., 2005). In addressing and responding to these tasks, workers incrementally remake their occupational practices through their everyday activities and, in some instances, transform them (Donald, 1991). When something entirely new arises for the occupation, such as innovative technology, customer demands, ways of working and so on, individuals can utilise what they know, can do and value as they enact changing work requirements and, thereby, transform their occupational practice. So, as individuals think and act in and through their work, a co-occurrence of learning and the remaking and, in some instances, transforming of the cultural 
practices that comprise their occupations arises. Therefore, remaking culture and cultural practices such as occupations is not wholly subject to the actions of others (e.g. teachers or experts), but is something arising through individuals' thinking and acting and mediation of what they experience, such as when engaged in their work.

Thirdly, it is important to delineate the learning referred to above from development. Learning is what occurs moment-by-moment or micro-genetically as people engage in thinking and acting (i.e. construing and constructing knowledge from what we experience) (Hutchins, 1993; Pea, 1997; Rogoff, 1990). That construal of experience and construction of knowledge is premised upon what we already know, can do and value arising from earlier experiences (Valsiner, 1998). The legacy of that earlier experiencing is referred to as ontogenetic development: the accumulation of our knowing and knowledge from across life histories (Pea, 1997; Rogoff, 1990; Vygotsky, 1987). As we engage what we know, can do and value to activities and interactions in work settings, moment-bymoment learning or micro-genetic development arises that is both shaped by, but also shapes, ontogenies (individuals' ontogenetic development). This development and learning is necessarily person-dependent as the nature of experiences and processes of experiencing are person-specific (Valsiner, 2000). All of this privileges personal bases for how learning arises, particularly through the apprenticeship mode of learning, because it is individually mediated, but also when individuals engage models of education including those called apprenticeships.

Fourthly, when considering apprenticeships as both a mode of learning and model of education, it is helpful to differentiate between personal and institutional facts. Personal facts are a product of and organised by people themselves, for instance, how and what is learnt from particular experiences based on their personal epistemologies (i.e. what they know, value and can do) (Billett, 2009). As noted, that learning is premised upon their personal histories (i.e. ontogenetic development). Hence, apprenticeship as a mode of learning is a personal fact. Then, there are institutional facts (Searle, 1995) that are a product of the social world. These include occupations, educational provisions and workplace norms and practices that constitute what experiences are provided through activities and interactions in educational programs and workplaces alike. Education provisions arise through history, are shaped by government and church and are manifested in particular institutions and, therefore, are institutional facts. Hence, apprenticeships as models of education are such facts.

\section{Apprenticeship as a model of education}

There is long history of organised occupational preparation (Barbieri-Low, 2007; Bennett, 1938; Lodge, 1947). However, the origins of contemporary vocational education systems are usually found in the formation of modern nation states and/or industrialisation (Deissinger, 1996; Gonon, 2009). For instance, institutionalised apprenticeship arrangements were established to overcome skill deficits (Deissinger, 2002; Greinert, 2002), to avoid unemployment amongst young people, and to be aligned with, but not reliant upon, these new nation states (Gonon 2009). Vocational education including models of apprenticeships have become enacted through bureaucratic control and means (Frommberger and Reinisch, 2002; Hanf, 2002). Hence, they have come to serve states' interests and institutions, building on earlier institutional roles (e.g. guilds) previously held in the organisation and regulation of skilled work, albeit now through bureaucratic means.

Manifestations of apprenticeship models of education have come to differ widely across nation states because of the particular purposes they serve, the historical moment of their formation and the institutional arrangements and societal sentiments that govern their form and 
enactments (Frommberger and Reinisch, 2002). The German dual apprenticeship system with its two sets of experiences (i.e. workplace and vocational school) became available to sustain occupational preparation across a wide range of occupations and as a mass form of transition to working life post the Second World War. This system is characterised by and premised upon strong collaboration and coordination at the local level between workplaces and vocational schools, albeit supported by a strong cultural sentiment associated with skill development (i.e. Berufskonzept) (Deissinger and Hellwig, 2005). Similarly, Swiss apprenticeships are available in a wide range of occupations as a provision of mass occupational preparation for school leavers. Beyond experiences in workplaces and vocational schools, this model features specialist training centres (i.e. the third space) to address any shortcomings of apprentices' particular workplace learning experiences (Perellon, 2003). Recently, and conversely, Sweden and Denmark have instituted apprenticeship arrangements that are "school based". The apprentices are students based in educational institutions and attending workplaces, but not as employees, which is distinct from the German, Swiss, Australian and New Zealand approaches to apprenticeship (Berglund and Loeb, 2013). Then, there is the $2+2$ model adopted in Norway in which apprentices spend 2 years in the vocational college and 2 years in the workplace.

Whilst the above apprenticeship models of education are nationally consistent, this is not always the case. In the United States, apprenticeships are a rarity and can be organised by unions, as is the case in Illinois in the construction sector (Worthen and Berchman, 2010). In the United Kingdom, apprenticeship models of education can also differ within and across industry sectors with some being intensively work based, with apprentices being employees, and others having apprentices largely as students in vocational colleges who engage with workplaces on varying bases and with varying frequency (Billett, 1997; Deissinger, 2002), yet rarely to the extent of the workplace-based approaches mentioned above. These distinct apprenticeship models of education are the product of particular imperatives, institutional arrangements and historical moments (Hanf, 2002): institutional facts.

It follows that characteristics of apprenticeship as model of education, including governance arrangements, are often highly institutionalised, based on bipartite or tripartite arrangements representing the interests of government, employers and employees in varying degree. As such, these models are subject to governmental and societal imperatives. Yet, their enactment is also subject to societal sentiments, such as the Berufskonzept mentioned earlier, or the more laissez faire approach of the United Kingdom that resists national uniformity and regulation, or the way in which the French republican sentiment works against close associations between education and work (Veillard, 2015), leading to apprenticeships being far less prominent there than in Germany and Switzerland. These sentiments are also subject to societal disdain in the form of low parental preference (Cho and Apple, 1998), not being valued like more "academically-oriented" educational processes and outcomes (Remery and Merele, 2014) and, therefore, subject to constraints in terms of resourcing (Veillard, 2015). As noted, apprenticeship as models of education positions apprentices variously as students, nascent practitioners, labour market entrants or low academic achievers and so on. This positioning is a product of and enacted through institutional arrangements, societal sentiments and decision-making about and for these provisions of education that are often shaped by powerful interests such as government, employers and unions, and that also can exclude the voices of those who teach, are positioned as apprentices, and those practising the occupations to be learnt. So, a range of institutional facts (Searle, 1995) shape this model of educational provisions. 
Yet, despite the central role of these institutional facts, ultimately the success of these different kinds of apprenticeship models is not wholly premised on institutional arrangements or what they afford apprentices in workplace and education settings. Instead, how apprentices elect to engage with what is afforded them, direct their efforts intentionally and apply to their work what they have learnt through this educational provision, are central to their success as models of education.

These apprenticeship models of education have become the orthodox and common means of occupational preparation in some countries. Indeed, it may be difficult for those of us living in schooled societies to envisage how skills were developed before the formation of national education systems and in the absence of educational models. Certainly, before modernity and the formation of modern nation states, institutional arrangements existed, such as guilds and apprentices' indentures, periods of journeymanship (i.e. day-labour) and societal imperatives associated with apprentices (Bennett, 1938). Yet, many of these institutions were focused on the provision of apprenticeships for societal regulatory purposes, rather than for promoting apprentices' learning. For instance, in 1601 the British Poor Law stated that parishes had responsibility to care for illegitimate, paupered or orphaned children, and making them apprentices became a strategy to avoid them being a burden upon the parish (Bennett, 1938). There were also conventions and practices associated with apprenticeships, such as the agreement reached in Regensburg in 1459 that across Europe masonry apprentices would not pay for their apprenticeships, and other examples far earlier in Early Imperial China (Barbieri-Low, 2007). Yet, these arrangements are focused on apprenticeships addressing institutional concerns, rather than focusing on apprentices' learning. This, it seems, was the responsibility of apprentices.

\section{Apprenticeship as a mode of learning}

Apprenticeship as a mode of learning has been the most common means of developing occupational capacities across human history. Most likely the vast majority of occupational preparation has arisen through individuals' active and personally-mediated learning outside of institutionalised educational provisions (Billett, 2014). That preparation has been essential for human survival and progress over the last 10,000 years at least, since humans have lived in settled communities and cities. Without the development of the occupational capacities to provide food, shelter and services that humans need, our societies would not have been sustained or developed to what they are today. The evidence suggests that across this time, teaching or close guidance by more expert partners was a relative rarity. Most contemporary examples of analogous learning fail to identify direct teaching and instead emphasise learning through the lived experience of the occupational practice (Bunn, 1999; Jordan, 1989; Lave, 1990; Marchand, 2008; Singleton, 1989). It seems that the kind of close guidance or teaching that is taken as orthodox in modern "schooled" societies is a product of modernity (Jordan, 1989). Before that time, individuals learnt, rather than being taught (Donald, 1991; Webb, 1999). In many ways this is hardly surprising, given that even in the educational institutions the mode of learning was rarely through didactic processes, and the vast majority of the population would not have experience of even these kinds of educational processes, and that teaching as we understand it and experience it through schooling was in the distant future.

The evidence suggests that the key process through which occupational development occurred across these millennia was mimesis (i.e. observation, imitation and practice) or mimetic learning (Billett, 2014). Although in contemporary times there is a tendency to be sceptical of 
learning processes not directly supported by teachers, trainers or experts (Jordan, 1989), this mode of learning appears to be the case across much of human history.

... the didactic mode ... has always been a minor mode of knowledge acquisition in our evolutionary history. In the west, however, the didactic mode of teaching and learning has come to prevail in our schools to such an extent that is often taken for granted as the most natural, as well as the most efficacious and efficient way of going about teaching and learning. This view is held despite the many instances in our own culture of learning through observation and imitation. (Jordan, 1989, p. 932)

Indeed, learning through observation and imitation (i.e. mimetic learning) stands as a foundational process through which humans have construed and constructed knowledge across our history. Family and local workplaces were the sites for this form of learning occupations in Europe (Greinert, 2002), India (Menon and Varma, 2010), Japan (Singleton, 1989) and China (Ebrey, 1996). Central to this mode of learning across these regions is learners' active engagement and construction of knowledge (Webb, 1999). The word apprenticeship arises from the French word "apprehende" - the imperative for learners to apprehend or seize the knowledge that needed to be learnt from what was being enacted around them. This concept is evident in contemporary inquiry. Marchand (2008) writes of apprentice masons in the Middle East having to seize or steal the knowledge they needed to learn from experienced masons when building minarets. The apprentices had to gain access to and interact with masons through demonstrating their competence in supporting their work, to learn the procedures and approaches needed in that work through observation and imitation. This knowledge was not directly passed on to them through direct guidance or teaching: they had to actively engage and learn it. Moreover, the Japanese word for apprentice is "minarai" which refers to what "one learns by observation" (Singleton, 1989). There is even a term associated with unobtrusive observation (i.e. minarai kyooiku). Indeed, Singleton (1989) suggests that "it is expected that serious learning will proceed mediated by didactic instruction" ( $p$. 25). Yet, apprentices even have to learn this fact.

So, across human history and different cultures, the common means of acquiring occupational capacities has been through a mode of learning called apprenticeship. In contrast to apprenticeship as educational model, this conception is largely premised upon learners' active engagement in their work and learning (i.e. apprehending), albeit in interdependent ways. Rather than being dependent on others (e.g. teachers, experts, "meisters", etc), this mode of learning progresses through learners engaging interdependently within physical and social environments. This mode includes apprentices identifying what needs to be learnt, knowing how that knowledge is acquired and actively engaging to acquire it, and monitoring engagement and development (Marchand, 2008; Singleton, 1989), that is, through apprentices actively engaging, apprehending and appraising what those contributions provide for them -- interdependently, rather than being taught.

However, this is not to suggest that this mode of learning is ideal or without shortcomings or problems. Instead, and importantly, it comprises an explanation of how people have learned and likely learn occupational practices amongst others. For instance, this mode of learning does not necessarily meet the contemporary requirements of work and working life. Much of the knowledge required in contemporary kinds of work and workplaces has high levels of symbolic conceptual knowledge that are difficult to observe or access (Barley, 1992) or, therefore, to learn through discovery alone. Also, in earlier times, apprentices were often immersed in the occupational practice 
as it was occurring within their family and home (Greinert, 2002; Lave, 1990), which is not the case for the majority of apprentices learning in contemporary times.

Yet, these processes are also foundational for human learning and development (Byrne and Russon, 1998; lacoboni, 2005) and these processes underpin learning that extends to what occurs through apprenticeship as model of education. Therefore, it is useful to identify ways in which these contributions can support apprenticeship as a mode of learning in, through and for occupational practice.

\section{Key elements of enacting apprenticeship as a mode of learning}

Drawing on earlier empirical work and from a review of historical, anthropological and developmental literature, three broad elements of apprenticeship as a mode of learning outside of educational practices and institutions have been identified: (a) practice curriculum - access to, organisation and ordering of apprentices' experiences; (b) practice pedagogies - means of augmenting learning experiences in practice settings, and (c) learners' personal epistemologies how learners come to engage with and contribute to the learning process. An account of promoting apprenticeship as a mode of learning is now advanced through an overview of these elements.

\section{Practice curriculum}

There are two dimensions to the practice curriculum that support apprenticeship learning. First is engaging in the lived experience of working in a particular work community over time (Bunn, 1999; Jordan, 1989; Rogoff, 1990), that is, the process of experiencing and learning afforded through everyday work activities. Second is the deliberate structuring of experiences required because the activities and interactions required to secure the occupational knowledge might not otherwise be available or accessible. For example, safety training might be conducted because this is important learning and it is undesirable to wait until accidents are experienced before being learnt. Also, these required learning experiences may be simply unavailable. In Bunn's (1999) study, access to some occupations (e.g. blacksmithing, yurt making) required deliberate engagement (i.e. being apprenticed to families where these occupations are practised).

Immersion in the lived experience of work communities is probably the most long-standing and commonest means for learning occupations. This immersion is often consistent with the original meaning of the word curriculum: the pathway of experiences to progress along (Marsh, 2004). Anthropological studies identify different kinds of pathways used in work settings as a means for apprentices to progress along. Lave (1990) refers to the learning curriculum comprising a pathway of activities shaped by progressing from those where the consequences of workplace errors are low through to those where the consequences of errors are greater. She noted that Angolan tailoring apprentices learnt by progressing through engaging in a sequence of activities beginning with finishing garments, then making children's underwear, adults' undergarments, children's shirts, adults' shirts and onto garments whose fabric was expensive and errors came at great cost. This sequencing has important pedagogic properties. Initially, the apprentices get to observe the quality of finished garments they have to achieve, and are given opportunities for honing their skills progressively and demonstrating competence progressively along the sequences of tasks and garments. Similar pathways were identified for apprentice hairdressers as they progress from engaging in "tea and tidy" (i.e. offering customers hot beverages and keeping the workplace tidy) then on to washing clients' hair, washing out chemicals and surplus dyes from hair, through placing curlers and rods in clients' hair, and then learning to cut hair (Billett, 2011). However, models of 
practice curriculum can progress on other bases than error costs. Apprentice potters' access to the potting wheel, for instance, was the key basis for their developmental pathway (Singleton, 1989). As these wheels are required for production, they had to be accessed by apprentices outside of those times when they would be required for productive purposes. The pathway here involved processes of observations of potters using the wheel, prior to engaging with it. Then, after they had developed and demonstrated an ability to use the wheel, the apprentices were assigned regular practice, and then when their products became saleable, they engaged in productive tasks and sufficient work to pay back the potter for their apprenticeship. Other models exist in which each step has potentially high errors risk (e.g. doctors) (Sinclair, 1997) and close supervision is required. Then, there is parallel practice, where the novice engages in the occupational practice adjacent to the more experienced worker who checks their work before critical decisions are made (Billett and Sweet, 2015).

So, in different ways, workplace requirements and processes set the particular pathway of experiences that constitute the practice curriculum and its enactment. In this way, the deliberate structuring of experiences responds to imperatives of work practice, but also to the need for novices to learn and remake its practices. So, whilst apprenticeships as a mode of learning are supported by engaging in the lived experience of workplaces, there is a deliberate structuring of workplace activities that meet the goals of individuals' learning and also of sustaining and advancing the workplace's practices. These concepts of curriculum have similarities with those adopted in educational institutions (Billett, 2011). Just as those in educational institutions are premised on what is afforded by those institutions, so are experiences in work settings.

Yet, on their own, the ordering and provision of experiences may be insufficient, particularly when the kinds of knowledge required to be learnt contemporaneously by apprentices cannot be secured through just engaging in the lived experience of workplaces. Hence, practice pedagogies are required that can augment and enrich what is afforded by the practice curriculum.

\section{Practice pedagogies}

Pedagogies are means by which experiences can be enriched or augmented to promote particular kinds of learning. These are what teachers utilise in classrooms to promote student learning in educational settings. However, practice pedagogies identified in anthropological, historical or sociocultural literature are those that either arise in or can be enacted through everyday work activities and interactions. Like teaching strategies, some are associated with what more experienced workers can do to assist novices' learning. For instance, storytelling (Jordan, 1989) and verbalisation (Gowlland, 2012) and the use of heuristics and mnemonics (Sinclair, 1997) are means by which these workers can provide instances, articulate their thinking and acting, and offer guidance as they conduct their work activities. Storytelling provides narratives that assist recall of facts, concepts or propositional links, as can mnemonics (i.e. devices to remember and recall knowledge). Verbalisation makes accessible to novices accounts of experts' thinking as they enact work tasks. Mnemonics are means by which knowledge can be remembered and recalled (Rice, 2008). For instance, doctors can use them to recall the complex of factors comprising particular medical conditions by reference to the first patient in whom they encountered those conditions (Sinclair, 1997). Much of that learning is about propositions, concepts and causal associations amongst concepts, such as occurs when engaging in problem-solving activities such as clinical reasoning. Then, heuristics or "tricks of the trade" promote procedural capacities (i.e. how things are done). These procedures are derived from practice and likely to achieve specific outcomes. There are also sets of distinctly pedagogic activities used by more experienced partners, including modelling 
process, providing close guidance to develop capacities, coaching individuals and progressive withdrawal of support referred to as scaffolding (Collins et al., 1989) that can extend to the use of artefacts to make accessible what cannot be directly experienced (Pelissier, 1991). This direct interaction extends to more experienced co-workers placing their hands on those of novices to assist the development of haptic capacities that are difficult to articulate (Gowlland, 2012; Makovichy, 2010). This kind of support for learning through apprehending is what Ingold (2000) refers to as guided discovery: how more experienced workers guide apprentices' thinking and acting.

Yet, not all pedagogic practices are those provided and enacted by more experienced workers. The physical and social environment of workplaces also supports learning pedagogically. Some work activities are inherently pedagogically rich. For instance, nurses' handover meetings are an example of these kinds of activities as patients, their conditions, treatments, responses and prognoses are discussed by the nurses. These processes permit the articulation of concepts about health care and appraisal of procedures used through evaluations of their relative effectiveness. Also, these activities can be engaged with by learners at different stages in their development. This kind of activity is also potentially useful for developing depth in conceptual knowledge (i.e. understanding), considered and strategic use of procedures, and development of values associated with work. Importantly, these pedagogically-rich activities can occur through everyday work activities (i.e. they do not need to be deliberately structured or constructed). Similarly, workers' access to partially-worked examples (Makovicky, 2010) provides means by which physical and social environments provide clues and cues about how and when to act (Lave et al., 1984), thereby shaping the goals for learning indirectly.

Each of these pedagogic practices can be directed towards particular kinds of learning. Some establish goals for learning; others prompt recall and augment linkages and associations that aid conceptual and procedural development and promote work-related dispositions. Importantly, these practices are enacted as part of everyday work activities and make particular contributions to apprehending the knowledge to be learnt. Yet, the efficacy of these pedagogic practices is largely mediated by individuals' engagement with them, which reminds us that the augmentation provided by these pedagogic practices is shaped by learners' engagement with and apprehending of what they have experienced. Hence, central here is how learners apprehend and mediate that learning which is premised on their personal epistemological practices.

\section{Personal epistemologies}

Ultimately, therefore, regardless of what experiences are afforded in workplaces and educational institutions, learning arises through how individuals come to engage with those experiences. Hence, experiencing (i.e. how they construe and construct what they experience) is central to apprenticeship as a mode of learning. Essentially, personal epistemologies are bases of individuals' active knowing, engaging and learning. These attributes are more than beliefs, and extend to what individuals know and can do, including their embodied knowledge (i.e. that which they engage in without conscious thinking). Included here is their sense of self (i.e. how they view themselves), the agency (i.e. how they direct their intentional efforts in work and learning), their intentionality (i.e. the focus and direction of the conscious efforts at work and learning) and also their introspection (i.e. how they engage with what they experience). It also includes them knowing how to act to learn effectively (Singleton, 1989). These personal practices include engagement in mimetic learning (i.e. observation, imitation, practice), and how they come to engage with others from whom they might learn. All of this is premised on the active engagement and construction of knowledge: their 
apprehending of what they experience (Webb, 1999). Here, the concept of readiness also plays out - the degree by which apprentices have the understandings to engage effectively with what they experience, and the procedural capacities (i.e. skills) to engage effectively in activities and extend what they can do, underpinned by their dispositional readiness (Billett, 2015b). In other words, it relies on their values, interests and dispositions associated with engaging in activities and interactions from which they learn their occupational practices. It has been noted that those who perform exceptionally well often do so because they have engaged deliberately in practice (Ericsson, 2006). So, all of this refers to the personal epistemological practices individuals use to mediate what they experience and learn.

In sum, this section proposes that the apprenticeship mode of learning can be enriched and augmented by the practice curriculum and pedagogies, and yet, ultimately, these are mediated by learners' personal epistemologies as they apprehend knowledge. Different kinds of practice curriculum are premised on workplace requirements and particular kinds of pedagogic practices are directed towards specific learning outcomes. Yet, there can be no guarantee they will be enacted frequently or in ways to secure the requirements for effective practice. What is suggested is that these practices can be used to promote and support apprentices' learning in workplaces.

\section{Implications}

Understanding more fully and effectively advancing apprenticeships both as models of education for and a mode of learning occupational capacities is central to developing and sustaining occupational competence. The sections above have set out some premises and processes by which apprenticeship as a mode of learning might be considered and enacted, and these also have relevance to contemporary educational models of apprenticeship. Hence, it is worth identifying implications from apprenticeship as a mode of learning with what is being enacted within educational models of apprenticeship.

\section{School-based models of apprenticeship}

In models of apprenticeship based in educational institutions, where apprentices are positioned as students, it is important to emphasise these learners having to actively apprehend the knowledge they need to learn, and in different ways than occurs in the transmission of knowledge through schooling (i.e. teacher-led and dependent ways). Instead, likely, such student-apprentices need to exercise agency and intentionality in appropriating what they experience in practice settings. Hence, teachers might be directed towards supporting and aligning students' experiences in both educational and workplace settings with the kinds of educational goals to be achieved -- that is, actively facilitating and supporting apprentices' processes of experiencing. For instance, there is likely to be value in engaging with them before, during and after their workplace experiences to prepare them for those experiences, to support them during their engagement and, perhaps most importantly, to assist them to reconcile, share and compare with others what they have experienced in practice settings (Billett, 2015a). Also, part of this educational process is to promote their sense of selves as worker-learners, which may be far more difficult to secure than for those who are largely based in work settings.

\section{Work-based models}

Given the importance of apprentices mediating their learning in work settings, they need to be adequately prepared for this role, including a shift away from dependence upon others and an 
emphasis on interdependence. Part of this preparation is to emphasise the importance and necessity of engaging effortfully in the activities and interactions of their work settings. Also, associated with work-based models of apprenticeship is finding ways of promoting, utilising and monitoring the kinds of practice curriculum and pedagogic practices enacted to support apprentices' learning. There is much knowledge that apprentices will not be able to learn through discovery alone; hence, there is a need to engage with others to make accessible these kinds of knowledge.

\section{Apprenticeship as a model of learning}

They key point advanced here is to consider apprenticeships primarily as a mode of learning that is essential to, and can be supported, augmented and extended by, educational processes. Ultimately, it is individuals' apprehending of the knowledge that they need to learn that is central both to this mode of learning and models of education. As noted, there are different kinds of educational models that seek to engage apprentices' learning in distinct ways to achieve occupational outcomes. The degree by which these are able to be effective is often constrained by practical considerations associated with the range and diversity of experiences afforded in work settings. Hence, consideration needs to be given to pathways of experiences (i.e. practice curriculum) and how they can be augmented (i.e. practice pedagogies) to achieve what workplaces and apprentices want learnt: occupational capacities. Hence, there is a need to enhance awareness about practice pedagogies, and promote their use to support apprenticeship as a mode of learning and a model of education. Yet, beyond what is afforded in the workplace, how apprentices come to engage in their work and learning is salient. Securing the kinds of knowledge required for occupations necessitates active and enduring effortful engagement in working and learning. Consequently, central here, also, are apprentices' capacities to work and learn interdependently, with others and with artefacts, and to do so in ways that are intentional and well directed. Hopefully, the understandings from studies of learning outside of educational institutions can be of assistance here.

\section{References}

Anderson, J.R. (1993), "Problem solving and learning", American Psychologist, Vol. 48, pp. 35-44. Baldwin, J.M. (1894), "Personality-Suggestion", Psychological Review, Vol. 1, pp. 274-279.

Barbieri-Low, A.J. (2007), Artisans in Early Imperial China, University of Washington Press, Seattle. Barley, S. (1992), The New Crafts: The Rise of the Technical Labour Force and its Implication for the Organization of Work, University of Philadelphia, National Center on the Education Quality of the Workforce, Philadelphia, PA.

Bennett, C.A. (1938), "The ancestry of vocational education", in Lee, E.A. (Ed.), Objectives and Problems of Vocational Education, 2nd ed., McGraw-Hill Book Company, New York, NY, pp. 1-19.

Berglund, I. and Loeb, I.H. (2013), "The renaissance or a backward step: disparities and tensions in two new Swedish pathways in VET", International Journal of Training and Research, Vol. 11 No. 2, pp. 135-149.

Billett, S. (1997), "Factors in vocational education policy development: modern apprenticeships, a case study", Australian Vocational Education Review, Vol. 4, pp. 51-60.

Billett, S. (2001), Learning in the Workplace: Strategies for Effective Practice, Allen and Unwin, Sydney.

Billett, S. (2003), "Sociogeneses, activity and ontogeny", Culture and Psychology, Vol. 9, pp. 133-169.

Billett, S. (2009), "Conceptualizing learning experiences: contributions and mediations of the social, personal and brute", Mind, Culture and Activity, Vol. 16, pp. 32-47. 
Billett, S. (2011), "Workplace curriculum: practice and propositions", in Dochy, F., Gijbels, D., Segers, M. and Van den Bossche, P. (Eds.), Theories of Learning for the Workplace: Building Blocks for Training and Professional Development Programs, Routledge, London, pp. 17-36.

Billett, S. (2014), Mimetic Learning at Work: Learning in the Circumstances of Practice, Springer, Dordrecht, The Netherlands.

Billett, S. (2015a), Integrating Practice-based Learning Experiences into Higher Education Programs, Springer, Dordrecht, The Netherlands.

Billett, S. (2015b), "Readiness and learning in healthcare education", Clinical Teacher, Vol. 12, pp. 16.

Billett, S \& Sweet, L (2015) Understanding and appraising healthcare students' learning through workplace experiences: Participatory practices at work, in Eds Cleland, J \& Durning, S Researching Medical Education, (pp.117-127) Wiley, Oxford, UK

Billett, S., Smith, R. and Barker, M. (2005), "Understanding work, learning and the remaking of cultural practices", Studies in Continuing Education, Vol. 27, pp. 219-237.

Bunn, S. (1999), “The nomad's apprentice: different kinds of 'apprenticeship' among Kyrgyz nomads in Central Asia", in Ainley, P. and Rainbird, H. (Eds.), Apprenticeship: Towards a New Paradigm of Learning, Kogan Page, London, pp. 74-85.

Byrne, R.W. and Russon, A. (1998), "Learning by imitation: a hierarchical approach", Behavioral and Brain Science, Vol. 21, pp. 667-721.

Chan, S. (2013), "Learning through apprenticeship: belonging to a workplace, becoming and being", Vocations and Learning, Vol. 6, pp. 367-383.

Cho, M.K. and Apple, M. (1998), "Schooling, work and subjectivity", British Journal of Sociology of Education, Vol. 19, pp. 269-291.

Collins, A., Brown, J.S. and Newman, S.E. (1989), "Cognitive apprenticeship: teaching the crafts of reading, writing and mathematics", in Resnick, L.B. (Ed.), Knowing, Learning and Instruction: Essays in Honor of Robert Glaser, Erlbaum \& Associates, Hillsdale, NJ, pp. 453-494.

Deissinger, T. (1996), "Germany's Vocational Training Act: its function as an instrument of quality control within a tradition-based vocational training system", Oxford Review of Education, Vol. 22, pp. 317-336.

Deissinger, T. (2002), "Apprenticeship systems in England and Germany: decline and survival", in Greinert, W.-D. \& Hanf, G. (Eds.), Towards a History of Vocational Education and Training (VET) in Europe in a Comparative Perspective, Proceedings of the First International Conference, October 2002 Florence, Vol. 1, Office for Official Publications of the European Communities, Luxembourg, pp. 28-45.

Deissinger, T. and Hellwig, S. (2005), "Apprenticeships in Germany: modernising the dual system", Education and Training, Vol. 47, pp. 312-324.

Donald, M. (1991), Origins of the Modern Mind: Three Stages in the Evolution of Culture and Cognition, Harvard University Press, Cambridge, Massachusetts.

Ebrey, P.B. (1996), China: Illustrated History, Cambridge University Press, Cambridge, United Kingdom.

Ericsson, K.A. (2006), "The influence of experience and deliberate practice on the development of superior expert performance", in Ericsson, K.A., Charness, N., Feltowich, P.J. and Hoffmann, R.R. (Eds.), The Cambridge Handbook of Expertise and Expert Performance, Cambridge University Press, Cambridge, pp. 683-704.

Frommberger, D. and Reinisch, H. (2002), "Development of disparate structures of Dutch and German vocational education", in Greinert, W.-D. \& Hanf, G. (Eds.), Towards a History of Vocational Education and Training (VET) in Europe in a Comparative Perspective, Proceedings of the First International Conference, October 2002 Florence, Vol. 1, Office for Official Publications of the European Communities, Luxembourg, pp. 75-87. 
Gonon, P. (2009), '“Efficiency' and 'vocationalism' as structuring principles of industrial education in the USA", Vocations and Learning: Studies in Vocational and Professional Education, Vol. 2, pp. $75-86$.

Gowlland, G. (2012), "Learning craft skills in China: apprenticeship and social capital in an artisan community of practice", Anthropology and Education Quarterly, Vol. 43, pp. 358-371.

Greinert, W.-D. (2002), "European and vocational training systems: the theoretical context of historical development", in Greinert, W.-D. \& Hanf, G. (Eds.), Towards a History of Vocational Education and Training (VET) in Europe in a Comparative Perspective, Proceedings of the First International Conference, October 2002 Florence, Vol. 1, Office for Official Publications of the European Communities, Luxembourg, pp. 17-27.

Hanf, G. (2002), "Introduction”, in Greinert, W.-D. \& Hanf, G. (Eds.), Towards a History of Vocational Education and Training (VET) in Europe in a Comparative Perspective, Proceedings of the First International Conference, October 2002 Florence, Vol. 1, Office for Official Publications of the European Communities, Luxembourg, pp. 11-16.

Hasse, C. (2014), "The anthropological paradigm of practice-based learning", in Billett, S., Harteis, C. and Gruber, H. (Eds.), International Handbook of Research in Professional and Practice-based Learning, Springer, Dordrecht, pp. 369-391.

Hutchins, E. (1993), "Learning to navigate", in Chaiklin, S. and Lave, J. (Eds.), Understanding Practice: Perspectives on Activity and Context, Cambridge University Press, Cambridge, UK, pp. 35-63.

lacoboni, M. (2005), "Neural mechanism of imitation", Current Opinions in Neurobiology, Vol. 15, pp. 632-637.

Ingold, T. (2000), The Perception of the Environment: Essays on Livelihod, Dwelling and Skill, Routledge, London.

Jordan, B. (1989), "Cosmopolitical obstetrics: some insights from the training of traditional midwives", Social Science and Medicine, Vol. 28, pp. 925-944.

Lave, J. (1990), "The culture of acquisition and the practice of understanding", in Stigler, J.W., Shweder, R.A. and Herdt, G. (Eds.), Cultural Psychology, Cambridge University Press, Cambridge, UK, pp. 309-327.

Lave, J. (1993), "The practice of learning", in Chaiklin, S. and Lave, J. (Eds.), Understanding Practice: Perspectives on Activity and Context, Cambridge University Press, Cambridge, UK, pp. 3-32.

Lave, J., Murtaugh, M. and De La Roche, O. (1984), "The dialectic of arithmetic in grocery shopping", in Rogoff, B. and Lave, J. (Eds.), Everyday Cognition: Its Development in Social Context, Harvard University Press, Cambridge, Mass., pp. 67-94.

Lodge, R.C. (1947), Plato's Theory of Education, Routledge \& Kegan Paul, London.

Makovichy, N. (2010), "'Something to talk about': notation and knowledge-making among Central Slovak lace-makers", Journal of the Royal Anthropological Institute (NS), Vol. 16, pp. 80-99.

Marchand, T.H.J. (2008), "Muscles, morals and mind: craft apprenticeship and the formation of person", British Journal of Education Studies, Vol. 56, pp. 245-271.

Marsh, C.J. (2004), Key Concepts for Understanding Curriculum, RoutledgeFalmer, London.

Menon, J. and Varma, S. (2010), "Children playing and learning: crafting ceramics in ancient Indor Khera", Asian Perspectives, Vol. 49, pp. 85-109.

Pea, R.D. (1997), "Practices of distributed intelligence and designs for education", in Salomon, G. (Ed.), Distributed Cognitions: Psychological and Educational Considerations, Cambridge University Press, Cambridge, pp. 47-87.

Pelissier, C. (1991), "The anthropology of teaching and learning", Annual Review of Anthropology, Vol. 20, pp. 75-95.

Perellon, J.-F. (2003), "The creation of a vocational sector in Swiss higher education: balancing trends in system differentiation and integration", European Journal of Education, Vol. 38, pp. 357370.

Perkins, D., Jay, E. and Tishman, S. (1993), "Beyond abilities: a dispositional theory of thinking", Merrill-Palmer Quarterly, Vol. 39, pp. 1-21. 
Piaget, J. and Inhelder, B. (1973), Memory and Intelligence (A.J. Pomerans trans.), Basic Books, New York.

Remery, V. and Merele, V. (2014), "French approaches to accreditation of prior learning: practices and research", in Halttunen, T., Koivisto, M. and Billett, S. (Eds.), Promoting, Assessing, Recognizing and Certifying Lifelong Learning: International Perspectives and Practices, Springer, Dordrecht, The Netherlands, pp. 265-280.

Rice, T. (2008), "Beautiful murmurs: stescopic listening and acoustic objectification", The Senses and Society, Vol. 3, pp. 293-306.

Richards, J., Sweet, L \& Billett, S (2013). "Preparing medical students as agentic learners through enhancing student engagement in clinical education." Asia-Pacific Journal of Cooperative Education Vol 14: $251-263$

Rogoff, B. (1990), Apprenticeship in Thinking - Cognitive Development in Social Context, Oxford University Press, New York.

Rogoff, B. and Lave, J. (Eds.) (1984), Everyday Cognition: Its Development in Social Context, Harvard University Press, Cambridge, Mass.

Searle, J.R. (1995), The Construction of Social Reality, Penguin, London.

Shuell, T.J. (1990), "Phases of meaningful learning", Review of Educational Research, Vol. 60, pp. 531-547.

Sinclair, S. (1997), Making Doctors: An Institutional Apprenticeship, Berg, Oxford.

Singleton, J. (1989), "The Japanese folkcraft pottery apprenticeship: cultural patterns of an educational institution", in Coy, M.W. (Ed.), Apprenticeship: From Theory to Method and Back Again, SUNY, New York.

Valsiner, J. (1998), The Guided Mind: A Sociogenetic Approach to Personality, Harvard University Press, Cambridge, Mass.

Valsiner, J. (2000), Culture and Human Development, Sage Publications, London.

Van Lehn, K. (1989), "Towards a theory of impasse-driven learning", in Mandl, H. and Lesgold, A. (Eds.), Learning Issues for Intelligent Tutoring Systems, Springer-Verlag, New York, pp. 19-41.

Veillard, L. (2015), “University-corporate partnerships for designing workplace curriculum: alternance training course in tertiary education", in Filliettaz, L. and Billett, S. (Eds.), Francophone Perspectives of Learning Through Work: Conceptions, Traditions and Practices, Springer, Dordrecht, The Netherlands, pp. 257-278.

Vygotsky, L.S. (1987), Thought and Language (A. Kouzulin, Ed.), The MIT Press, Massachussets. Webb, E. (1999), "Making meaning: language for learning", in Ainley, P. and Rainbird, H. (Eds.), Apprenticeship: Towards a New Paradigm of Learning, Kogan Page, London, pp. 100-110.

Worthen, H. and Berchman, M. (2010), "Apprenticeships: what happens in on-the-job training (OJT)?", in Billett, S. (Ed.), Learning Through Practice, Springer, Dordrecht, The Netherlands, pp. 222-239. 